\title{
Manufacturing enterprise management concept focused on maximum customer engagement
}

\author{
Vadim Tynchenko ${ }^{1,2^{*}}$, Oksana Kukartseva ${ }^{1}$, Aygul Ogol $^{1}$, Andrei Yamshchikov ${ }^{2}$ and Aleksandr Bondarev ${ }^{1}$ \\ ${ }^{1}$ Reshetnev Siberian State University of Science and Technology, 31, Krasnoyarsky Rabochy Av., 660037 Krasnoyarsk, Russian \\ Federation \\ ${ }^{2}$ Siberian Federal University, 79, Svobodny Av., Krasnoyarsk, 660041, Russian Federation
}

\begin{abstract}
This article examines one of the main directions for improving the activities of structural units lean production, which is widely practiced abroad, but in Russian conditions it is mainly used by large manufacturing companies focused on the foreign market. The article discusses the methodology for the implementation of lean manufacturing. Seven types of losses were given, as well as a complete sequence of actions to eliminate them. We learned a value stream map, types of streams and their composition according to various factors. We examined the tools in the Lean Manufacturing system for the implementation of this technique. Also, enterprise management systems based on push and pull systems were described, diagrams for them were given that show the essence of the operation of these systems. At the end of the work, conclusions were drawn about the way to improve the enterprise, such as "lean manufacturing". The main objective of this article is to identify the essence and features of the research based on the principles of lean production in the structural unit of the research object.
\end{abstract}

\section{Introduction}

One of the most versatile ways to improve the performance of almost any enterprise is lean manufacturing. Its peculiarity lies in a thorough study of business processes and identification of all types of losses that may arise in the main production. Depending on the amount of losses and the ease of their measurement, a decision is made on specific measures to eliminate them [1-3].

The concept of "Lean Manufacturing" combines the optimization of production processes aimed at continuous improvement of product quality while constantly reducing costs, with the involvement of each employee in this process. The concept is maximally focused on market conditions of management. The main task of such production was the creation of competitive products in the required quantity, in the shortest possible time and with the least resource consumption [4-6].

The transition from conventional production to lean production indicates that the company has reconsidered its views on production relations within the enterprise, as well as on relations with suppliers and consumers, if necessary. Favorable conditions of the recent past - high consumer demand with a low supply of goods and services, contributed to the fact that the price of goods was set based on the costs of the enterprise for the production of products by adding often unjustified "cheating" [7-9].

However, over time, the market situation has changed. The market for goods and services gradually became saturated and became highly competitive. Offers from various manufacturers stimulate competition between domestic and foreign suppliers. A situation in which supply exceeds demand leads to a forced fall in the market price of goods and services, and, as a consequence, to a fall in the company's profits. The only way to avoid falling profits in such conditions is to reduce production costs, since prices for raw materials and resources are also determined by the market situation [10-12].

\section{Materials and Methods}

The possibility of reducing production costs is not always obvious to manufacturers: the consumption rates of raw materials and materials are being met, productivity is increasing. There is only one thing left to return to the analysis of the structure of production costs. First of all, expenses should be classified into those that are really necessary and those that can be eliminated. In terms of lean manufacturing, the ability of a product to meet consumer expectations is called value. The consumer is ready to pay only for the conformity of the characteristics of the product to his expectations (for functionality, quality, lead time, price, etc.). If in the production process any activity is carried out for which the consumer does not intend to pay, i.e. activity that does not add value, such an activity is called loss. Within the framework of lean production, the following types of losses are distinguished $[1,4]$ :

\footnotetext{
* Corresponding author: vadimond@mail.ru
} 
- losses due to overproduction - production of products that are not in demand; production of products in a larger volume earlier or faster than is required in the next stage of the process;

- wasted time due to waiting - interruptions in work associated with waiting for people, materials, equipment or information;

- losses due to excessive processing - additional processing of the product due to poor quality of the tool, design errors, etc.;

- loss due to unnecessary movement during operations any movement of people, tools or equipment that does not add value to the final product;

- losses due to excess inventory - any excess flow of products into the production process, be it raw materials, semi-finished products or finished products;

- losses during transportation - unnecessary movement or movement over long distances of materials, parts, products;

- losses due to the release of defective products products requiring inspection, sorting, disposal, replacement or revision.

Let's consider these losses in more detail. One of the most obvious ways to increase profits is to increase plant productivity. However, the pursuit of performance does not mean that there are enough consumers on the market who are willing to buy a particular product. A moment may come when a product that was previously lacking for everyone begins to accumulate in the warehouse. Then the management sets the task for sales managers to urgently sell everything, which is why they are forced to go out of their way to sell stale or spoiled goods. In this case, one cannot speak of any profit.

The main issue in this case is to compensate for the costs incurred, or even worse - to minimize losses. Ideally, they should be avoided and the solution to this problem here is quite simple. For this you need [1]:

- to produce only on time and only what the client wants (in fact, work only "to order");

- to produce goods in small batches, which are guaranteed to be sold (if demand falls, quickly switch to another type of product);

- to reduce losses during equipment changeovers, reduce changeover time to a minimum, making production in small batches profitable.

All this means that the profitability of production in large batches cannot be as efficient as it was previously thought. Today's customers are demanding. They need an assortment and variety right now, and losses due to storage of illiquid assets, due to excessive consumption of raw materials, due to problems with customers are not their concern.

Transportation losses. Any more or less complex production is a sequence of operations to transform raw materials, or semi-finished products into a final product. But between operations, all these materials need to be moved. Valuable transfer procedures are present even in conveyor production. After all, you need to deliver the raw materials to the conveyor or take the finished products to the warehouse. Of course, transportation is an integral part of production, only it does not create value at all, although it requires costs for fuel or electricity, for maintaining a transport fleet, for organizing transport infrastructure (roads, garages, overpasses, etc.). In addition, transportation is time consuming and risky because of product damage.

In order to reduce losses during transportation, it is necessary to create a map of the routes of vehicles and conduct a thorough analysis of the feasibility of one or another movement. After that, you should try to eliminate unnecessary transportation by redevelopment, redistribution of responsibility, elimination of removed stocks, etc. In the case of transportation, the system will not interfere: each movement of valuables must be justified by an appropriate regulatory document.

Losses due to waiting. This type of waste is associated with waiting for the start of material processing, and it indicates that the planning process and the production process are not coordinated with each other. This state of affairs is often found in the practice of domestic enterprises. The planning process itself is quite complex, since it requires the analysis of a large number of factors. These factors include: the structure of consumer orders, the state of the raw material market, equipment productivity, shift work schedule, etc. Truly optimal planning requires serious mathematical training and sophisticated interaction between sales, purchasing and manufacturing services. As a rule, the planning process is pseudo-optimal and is based on the subjective approach of people with some experience in production.

In addition to suboptimal scheduling, latency losses are significantly affected by uneven equipment throughput. In this case, the accumulation of products waiting to be processed can occur before the operation with the lowest throughput. The performance of such operations should be improved. If this is not possible, flexible equipment or redeployment of personnel between operations should be considered.

Losses from any inventory. Inventories reduce the free money supply of companies, which reduces the flow of profits and makes them dependent on lines of credit. But at present, the presence of stocks in production is considered quite common, and most importantly, a permissible phenomenon! Indeed, thanks to stocks, you can compensate for surges in consumer demand. Stocks allow the enterprise to produce products in case of interruptions in the supply of raw materials. Finally, inventory allows you to level the production flow. To answer this question, one should look at the problem of reserves from a different point of view [5]:

- Stocks are frozen circulating assets withdrawn from the circulating cycle.

- Stocks need maintenance (warehouse space, personnel, logistics, etc.).

- Inventories hide production problems: poor planning, strained relations with suppliers, uneven production flow, etc.

It turns out that stocks hide losses of other species, giving the impression of a safe working environment.

Losses due to manufacturing defects. The release of products that do not meet the requirements of the consumer entails obvious costs of raw materials, labor time, labor, processing costs and waste disposal. The traditional measure to reduce losses associated with the 
release of defective products is the organization of various controlling departments and services. It is believed that such units should take timely measures to prevent the release of scrap. But the fact that quality control services do not have the required leverage over production units is usually not taken into account. In any case, control is usually carried out only after the product has been manufactured. Consequently, the inspectors have no opportunity to influence the quality promptly. The only way out of this situation is to integrate quality management procedures into the production process.

Loss from over-processing. Earlier it was said that the consumer is ready to pay only for those properties of the product that are of value to him. If a consumer needs, for example, a smart phone, then he expects to receive a product of the appropriate quality, endowed with appropriate consumer properties for a certain price. Therefore, embedding a folding spoon in it, while doubling the price, is an unproductive activity that not only will not lead to more buyers, but, on the contrary, will push them away at its cost, because the additional functionality does not add any value to it.

The loss of over-processing should also include the maintenance of automatic equipment. For example, parts move along a conveyor that regularly stops due to skewing. A dedicated worker monitors the conveyor and corrects skewed parts. The labor of such a worker is also unnecessary processing and it is necessary to solve the root cause that lies in the conveyor. Its solution will lead to an increase in the speed of the conveyor itself and will reduce the cost of maintaining a special worker who corrects skewed parts.

Losses from unnecessary movements are typical of large enterprises. This type of waste can be described as meaningless fuss that does not add any value to the production process. From the outside, these movements may seem like hectic activity, but a closer look reveals that they, like the losses discussed earlier, do not contribute to the creation of value for the consumer. There is usually only one source of this type of loss poor work organization. These include the lack of necessary instructions, poor training of personnel or low labor discipline. This type of loss is distinguished by the fact that they can be detected quite easily, and once discovered, take quite obvious measures to eliminate them.

At the first stage, Lean Manufacturing describes possible losses, and at the second stage it already identifies them in order to eliminate them [12]. The approach that is proposed within the framework of the lean manufacturing concept is based on a mandatory, comprehensive and detailed understanding of the mechanism for creating customer value of the manufactured product. To this end, the first step is to draw up a detailed description of the entire production process. If the production is complex, then the whole process can be broken down into processes that are described and analyzed separately. To describe production processes, a visual schematic representation is used, called a value stream map. The complete sequence of actions to eliminate losses includes the following steps [2]:
- Development of maps for creating value stream of processes.

- Development of checklists to help identify the causes of losses at each stage of the process.

- Collection of statistical information about the time of value creation and the time of losses, as well as any other information indicating the presence of losses, using the developed checklists.

- Building a future value stream map (no loss).

- Analysis of the causes of losses and elimination of procedures that do not create value.

- Standardization of working procedures and use in other processes.

Further, the process can be repeated. In addition, targeted efforts can be made to eliminate certain types of waste with suitable lean tools (more on this later).

A value stream map is a detailed description of a manufacturing activity. In order for the value stream map to be as accurate as possible, the work steps must be strictly followed. When drawing up a map, one should not miss even small and at first glance insignificant details and works. If the movement of material assets is controlled by the document circulation system, then the views and trajectories of the documents being drawn up should be displayed on the map. Often it is the irrationality of the workflow that is the reason for the loss of time or the accumulation of stocks.

In production, the following types of flows are distinguished:

- Material flow (describes the movement of materials within production).

- Information flow (tells each process what to produce or what to do next).

- The flow of people or processes.

When analyzing the current state, the assessment is carried out according to the main factors. Resources:

- Determination of the range of work performed.

- Determination of the number of involved personnel.

- Determination of the amount of equipment involved.

Distance:

- Determination of all movements.

- Determination of the sequence of operations.

- Measuring the distance of each movement.

Time:

- Timing of operations.

- Timing of movements.

- Timing of the entire value stream.

Lean has its own tools. One of these is checklists, which are used to monitor and record results. They serve as primary documentary evidence reflecting the results of monitoring the performance of a particular production operation. Completing the checklists should be left to independent observers to eliminate the subjective component of the observations. Moreover, at the most critical points of observation, several independent monitors should be assigned. This will allow obtaining a consistent statistical sample of the observation results [13].

In the course of observations, inspectors should make records characterizing the peculiarities of the performance of a particular operation, as well as records indicating the possible presence of one of the types of 
losses. Based on the analysis of checklists, a decision is made on the presence or absence of losses in operations and a map of the value stream is drawn up, considering the desired state of the flow, after which they begin to eliminate the identified losses.

To eliminate losses, as well as to prevent their occurrence within the framework of lean production, many methods have been developed for the rational organization of production activities. Let's consider the most important ones, the use of which is a prerequisite for the successful implementation of a program for the implementation of lean manufacturing [11].

The first of these is a pull, which is a cascading production system in which the supplier (the employee of the subsequent operation of those processes), who is upstream, does nothing until the consumer, who is below, informs him about it (buyer's order - assembly release of parts - order to the supplier). Pulling allows you to reduce your inventory to almost zero.

Another approach to improving the production process is the flow of single items - a method of work in which a machine or process processes no more than one item at a time (creating a one-item flow) [3]. Advantages of one-piece flow [7]:

- Built-in quality. The flow of one-off items greatly simplifies the integration of quality. Each operator is at the same time a controller and one tries to solve the problem on the spot, without passing it on to the next stage. Even if he missed the defects, and they passed on, they will be detected very quickly and the problem will be identified;

- Genuine flexibility. If equipment becomes part of a production line, the ability to use it for other purposes will be reduced. The lead time is reduced to the limit, which means that you can more flexibly respond to the needs of the consumer, making what he really needs. Various 3D printers are an example of this approach. The flexibility of production increases, the transition to a new range of products, which requires a change in consumer demand, is carried out at the same time more quickly;

- Productivity increase. When the work is divided into departments, then the maximum productivity is estimated by the load of people and equipment. In fact, it is difficult to determine how many people it takes to make a given number of items in high volume production because productivity is not measured in terms of value-adding work. If there is a one-piece flow cell, then non-value-added work such as moving materials is minimized and you can see who is overwhelmed and who is idle at a glance.

- Freeing up areas in the shop. When equipment is distributed to sites, significant areas in between are lost and are often occupied by reserves;

- Increased security. One-piece flow will automatically lead to increased safety by reducing the amount of material that needs to be moved around the plant;

- Improving morale. The flow of one-off products means that most of the time people are busy creating added value and can quickly see the fruits of their labor, and when they see their successes, they feel satisfaction [10].
One of the losses discussed earlier was called waiting. Waiting loss occurs when parts exit from a previous operation but cannot be processed in the next. If the previous operation continues to produce parts, then another loss is formed - stock. If stocks grow too quickly, then it becomes necessary to transport them to the warehouse (another loss). As you can see, it is very important to submit parts for the subsequent operation only when the need arises. This method of work is called Just-In-Time, which involves working on order for the next operation. As with any custom work, this approach requires clear planning to achieve flexible equipment utilization. The main factor for successful planning is to reduce the amount of resources processed and transferred to the next operation and the use of methods to control the production flow.

\section{Results and Discussion}

Improvement of the main production should be based on the optimization of all types of flows discussed earlier. Materials management is carried out mainly in two ways: with a push-out control system and with a pull-out control system.

A push-out (pushing) control system is a material flow control system in which objects of labor are fed from a previous technological operation to a subsequent operation in accordance with a pre-formed schedule.

A production plan is developed for each shop and the implementation is monitored, and the system is shown in Figure $1[14,15]$.

A common drawback of a push system is insufficient tracking of demand with the mandatory creation of safety stocks [9]. In contrast to the pushing system, there is a pulling (pulling) control system in which objects of labor are fed from the previous stage of the production process to the next only when there is a need for them [16]. With this method of organizing production, the central system does not interfere with the exchange of material flows between sections of the enterprise, does not establish current production targets for them [8].

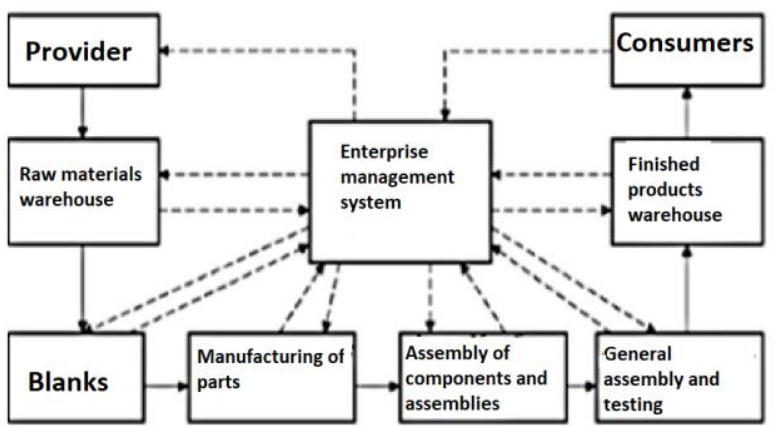

Fig. 1. Enterprise management system based on a push system.

\section{Conclusions}

One of the most versatile ways to improve the performance of almost any enterprise is lean manufacturing. Its peculiarity lies in a thorough study of business processes and identification of all types of 
losses that may arise in the main production. Depending on the amount of losses and the ease of their measurement, a decision is made on specific measures to eliminate them.

The production systems of "lean" enterprises are focused on the complete elimination of losses and continuous improvement of all processes. All employees of the company, from workers to senior management, are involved in the daily work of preventing all possible types of losses and continuous improvement. The company's management makes decisions that consider the prospect of further development, while momentary financial interests should not be decisive. The main thing on which the activities of not only the company's management, but also of each employee, should be concentrated is the timely detection, solution and prevention of problems and losses [6].

\section{References}

1. J. P. Wumek, D. Jone, Lean Manufacturing: How to get rid of losses and make your company prosper (Moscow, Alpina Publisher, 2018)

2. A.V. Vyalov, Lean production: a tutorial (Komsomolsk-on-Amur, FGBOU VPO "KnAGTU”, 2017)

3. V.D. Markova, S.A. Kuznetsova, Strategic management: concepts, concepts, decision-making tools: a reference guide (Moscow, INFRA-M, 2019)

4. I. Masaaki, The way to reduce costs and improve quality (Moscow, Alpina Publisher, 2017)

5. A.A. Boyko, V.V. Kukartsev, E.S. Smolina, V.S. Tynchenko, Y.I. Shamlitskiy, N.V. Fedorova, Jour. of Phys.: Conf. Ser. 1353, 012124 (2019)

6. N.V. Fedorova, V.V. Kukartsev, V.S. Tynchenko, Y.V. Danilchenko, S.N. Ezhemanskaya, N.V. Sokolovskiy, IOP Conf. Ser.: Mat. Sci. and Eng. 734, 012084 (2020)

7. S. Indrawati, A. Azzam, A.C. Ramdani, IOP Conf. Ser.: Mat. Sci. and Eng. 598, 012062 (2019)

8. V. Salnikov, D. Galimov, O. Mikheeva, A. Gnidchenko, A. Rybalka, Rus. J. of Econ. 3, 240 (2017)

9. N.F. Revenko, Organization of production and management at machine-building enterprises (Moscow, Higher school, 2017).

10. E.A. Chzhan, V.S. Tynchenko, V.V. Kukartsev, N.V. Fedorova, A.S. Yamshchikov, D.A. Krivov, IOP Conf. Ser.: Earth and Env. Sci. 315, 022106 (2019)

11. N.N. Pushina, N.G. Sokolova, V.P. Koretskiy, IOP Conf. Ser.: Mat. Sci. and Eng. 753, 062034 (2020)

12. E. Volkova, E3S Web of Conf. 244, 03023 (2021)

13. N. Havlovska, O. Illiashenko, O. Konoplina, I. Shevchuk, A. Hlynska, V. Prytys, TEM J. 9, 1053 (2020)

14. O.V. Demyanova, A. Kireeva-Karimova, L.M. Zabirova, J. of Eng. and App. Sci. 12, 4952 (2017)

15. E.L. Moskvicheva, A.M. Mukhametshina, A.N. Erofeyev, K.V. Savelyev, IOP Conf. Ser.: Mat. Sci. and Eng. 862042051 (2020)
16. A.A. Boyko, V.V. Kukartsev, K.Y. Lobkov, A.A. Stupina, Jour. of Phys.: Conf. Ser. 1015, 042006 (2018) 